\title{
Yoga, Physical Therapy, and Back Pain Education for Sleep Quality in Low-Income Racially Diverse Adults with Chronic Low Back Pain: a Secondary Analysis of a Randomized Controlled Trial
}

\author{
Eric J. Roseen, DC, MSc ${ }^{1,2}$, Hanna Gerlovin, PhD ${ }^{3}$, Alexandra Femia, MS ${ }^{7}$, Jae Cho, ', \\ Suzanne Bertisch, MD, MPH ${ }^{4,5}$, Susan Redline, $M D, M P H^{4,5}$, \\ Karen J. Sherman, $P h D, M P H^{6,7}$, and Robert Saper, $M D, M P H^{7}$
}

\begin{abstract}
'Department of Family Medicine, Boston University School of Medicine and Boston Medical Center, Boston, MA, USA; ${ }^{2}$ Department of Rehabilitation Sciences, Massachusetts General Hospital Institute of Health Professions, Boston, MA, USA; ${ }^{3}$ Slone Epidemiology Center, Boston University School of Medicine, Boston, MA, USA; “Division of Sleep and Circadian Disorders, Brigham and Women's Hospital, Boston, MA, USA; ${ }^{5}$ Division of Sleep Medicine, Harvard Medical School, Boston, MA, USA; ${ }^{6}$ Kaiser Permanente Washington Health Research Institute, Seattle, WA, USA; ${ }^{7}$ Department of Epidemiology, University of Washington, Seattle, WA, USA.
\end{abstract}

BACKGROUND: Poor sleep is common among adults with chronic low back pain (cLBP), but the influence of cLBP treatments, such as yoga and physical therapy (PT), on sleep quality is under studied.

OBJECTIVE: Evaluate the effectiveness of yoga and PT for improving sleep quality in adults with cLBP.

DESIGN: Secondary analysis of a randomized controlled trial.

SETTING: Academic safety-net hospital and 7 affiliated community health centers.

PARTICIPANTS: A total of 320 adults with cLBP.

INTERVENTION: Twelve weekly yoga classes, 1-on-1 PT sessions, or an educational book.

MAIN MEASURES: Sleep quality was measured using the Pittsburgh Sleep Quality Index (PSQI) global score (0-21) at baseline, 12 weeks, and 52 weeks. Additionally, we also evaluated how the proportion of participants who achieved a clinically meaningful improvement in sleep quality ( $>3$-point reduction in PSQI) at 12 weeks varied by changes in pain and physical function at 6 weeks.

KEY RESULTS: Among participants (mean age $=46.0$, $64 \%$ female, $82 \%$ non-white), nearly all (92\%) reported poor sleep quality (PSQI $>5$ ) at baseline. At 12 weeks, modest improvements in sleep quality were observed among the yoga (PSQI mean difference $[\mathrm{MD}]=-1.19$, 95\% confidence interval $[\mathrm{CI}]-1.82,-0.55)$ and PT (PSQI $\mathrm{MD}=-0.91,95 \% \mathrm{CI}-1.61,-0.20)$ groups. Participants who reported $\mathrm{a} \geq 30 \%$ improvement in pain or physical function at 6 weeks, compared with those who improved $<10 \%$, were more likely to be a sleep quality responder at 12 weeks (odds ratio $[\mathrm{OR}]=3.51,95 \% \mathrm{CI} 1.73,7.11$ and $\mathrm{OR}=2.16,95 \%$ CI 1.18, 3.95, respectively). Results were similar at 52 weeks.

Prior Presentations This work was presented, in part, at the Interna tional Research Congress on Integrative Medicine \& Health (May 2018) in Baltimore, MD, USA, and the International Back and Neck Pain Forum (July 2019) in Quebec City, Quebec, Canada.

Received November 14, 2018

Revised May 23, 2019

Accepted August 13, 2019

Published online October 30, 2019
CONCLUSION: In a sample of adults with cLBP, virtually all with poor sleep quality prior to intervention, modest but statistically significant improvements in sleep quality were observed with both yoga and PT. Irrespective of treatment, clinically important sleep improvements at the end of the intervention were associated with mid-intervention pain and physical function improvements.

TRIAL REGISTRATION: ClinicalTrials.gov Identifier: NCT01343927

KEY WORDS: back pain; chronic pain; yoga; physical therapy; education; sleep.

J Gen Intern Med 35(1): 167=76

DOI: $10.1007 / \mathrm{s} 11606-019-05329-4$

(c) Society of General Internal Medicine 2019

\section{BACKGROUND}

Sleep disturbance is common among persons with chronic low back pain (cLBP), with $59 \%$ and $53 \%$ experiencing poor sleep quality and insomnia disorder, respectively. ${ }^{1-3}$ The relationship between back pain and sleep disturbance is thought to be bidirectional, and therefore, interventions that improve both back pain and sleep quality may be ideal. ${ }^{4,5}$ Given the known adverse effects of pharmacologic therapy for both back pain and sleep disturbance (e.g., sedation, drowsiness, and confusion), as well as increased risk of overdose and death with concomitant use of opioid and benzodiazepine medications, ${ }^{6}$ there is a growing need to evaluate non-pharmacologic therapies for these prevalent and highly comorbid conditions. While cognitive behavioral therapy for insomnia (CBT-I) is an effective treatment for improving sleep quality, uptake of this non-pharmacologic approach has been constrained by a limited number of trained clinicians. ${ }^{7,8}$ In contrast, physical therapy (PT) and yoga are widely available. However, while both PT $^{9}$ and yoga ${ }^{10,11}$ have been shown to reduce pain and improve physical function in adults with cLBP, data on the impact of yoga and PT on sleep quality is sparse. 
Maintaining or initiating a regular exercise routine is a common recommendation for both cLBP self-care ${ }^{12}$ and sleep hygiene. ${ }^{13}$ Physical therapists, who commonly receive referrals from primary care physicians for cLBP, provide 1-on-1 care emphasizing strength training, aerobic exercise, and flexibility. ${ }^{14}$ In a systematic review, aerobic and resistance exercises improved sleep quality in middle-aged and older adults. ${ }^{15}$ Previous studies evaluating the effectiveness of exercise therapy for improving sleep demonstrate modest ${ }^{16-19}$ to large $\mathrm{e}^{20,21}$ improvements among older adults. Only one study of PT for sleep quality in older adults with cLBP found PT improved sleep quality to the same degree as a walking program and a group-based exercise course. ${ }^{22}$ However, that small study did not measure sleep quality immediately after the 8-week PT intervention-nor did they measure sleep quality over a longer follow-up period (e.g., 1 year). Thus, there is a need to further evaluate PT for sleep quality, particularly among young and middle-age adults with cLBP.

Yoga is a multi-factorial mind-body therapy that incorporates physical poses, rhythmic breathing, and meditation, and is growing in popularity in the USA. ${ }^{23}$ Previous studies have assessed the impact of yoga on sleep quality among diverse populations, including nurses, ${ }^{24}$ cancer patients, ${ }^{25-28}$ older adults, ${ }^{29-32}$ post or peri-menopausal women, ${ }^{17,33,34}$ and women with osteoarthritis. ${ }^{35,36}$ Furthermore, several studies have shown that yoga improves conditions related to poor sleep quality, such as anxiety and stress. ${ }^{37} \mathrm{~A}$ recent pooled analysis of clinical trials found yoga and exercise had similar small effects on sleep among menopausal women. ${ }^{17}$ We are unaware of any previous studies of yoga that assessed changes in sleep quality among adults with cLBP.

Recently, the Back to Health randomized controlled trial (RCT) found yoga to be non-inferior to PT for reducing pain and improving back-specific physical function among adults with cLBP. ${ }^{38,39}$ The goal of this paper was to perform a secondary analysis of Back to Health data to assess the effectiveness of yoga and PT, each compared with a back pain selfcare educational book, for improving sleep quality. We hypothesized that participants receiving yoga or PT interventions would experience a greater improvement in sleep quality at 12 and 52 weeks compared with participants receiving only the educational book.

\section{METHODS}

\section{Study Design}

The original randomized controlled trial of yoga, PT, and education as interventions for cLBP has been described elsewhere. $^{38,39}$ Briefly, 320 adults were randomized to a 12-week intervention phase and were subsequently followed over a 40week maintenance phase. During this trial, measures of comorbidity and disability were collected, including information on sleep quality. Staff performing data collection, entry, and analysis were masked to treatment assignment. The Boston
University Medical Campus Institutional Review Board approved the study prior to data collection. All participants provided written informed consent.

\section{Population}

English-speaking adults ages 18-64 who reported nonspecific cLBP, defined as $\geq 12$ weeks with an average pain intensity in the previous week of $\geq 4$ on an 11-point (0-10) numerical rating scale, were enrolled. Our analytic sample included 320 participants enrolled from June 2012 to November 2014 at a large academic safety-net hospital and 7 affiliated federally qualified community health centers located in diverse neighborhoods. Participants were randomized 2:2:1 to yoga, PT, or education.

\section{Interventions}

Our yoga intervention was designed specifically to aid cLBP in patients naïve to yoga and is described previously. ${ }^{38}$ Participants attended up to 12 weekly 75-min classes which included yoga poses, breathing, relaxation, and meditation. Instructors helped adapt yoga poses to participants' ability and we provided aids (e.g., chair, strap, blocks). Study staff and yoga instructors encouraged participants to practice yoga at home for 30 min daily using a DVD and home practice manual.

Our PT intervention included fifteen 60-min appointments over the course of 12 weeks. ${ }^{38}$ Each session included 1-on-1 work with the physical therapist and supervised aerobic exercise. Participants received written instructions and supplies for home practice and logged the number of exercises completed daily.

Education participants received The Back Pain Helpbook, including information on cLBP self-management, stretching, strengthening, and other self-care strategies, including a chapter on solutions for sleep problems. ${ }^{40}$ Every 3 weeks, participants received summary newsletters of assigned chapters and a 5- to 10-min check-in call from research staff.

Yoga and PT participants who attended at least one session in the 12-week intervention phase were eligible to participate in the maintenance phase (weeks 13-52). After the 12-week assessment, yoga participants underwent a second randomization in a 1:1 ratio to weekly drop-in yoga classes or home practice only. Similarly, PT participants were randomized to receive five booster sessions in the maintenance phase or home practice only. Participation in yoga/PT maintenance and home practice groups was similar and did not appear to influence 52-week pain and function outcomes. ${ }^{39}$ For analyses of sleep outcomes, the two yoga (home practice, drop-in classes) and PT (home practice, booster sessions) maintenance phase groups were combined to optimize power.

\section{Assessment of Sleep Quality}

Sleep quality was measured with the Pittsburgh Sleep Quality Index (PSQI), a widely used, validated measure of sleep- 
related function. ${ }^{41-43}$ The PSQI is a 19-item questionnaire composed of 7 subscales, where scores range from 0 to 3 , which correspond to distinct domains (habitual sleep efficiency, sleep disturbance, sleep duration, sleep latency, subjective sleep quality, sleep medication use, daytime dysfunction). Our primary outcome was the PSQI global score (0-21); higher scores indicate worse sleep quality. Prior studies define poor sleep quality with a score of $\geq 5$ and a clinically meaningful improvement as a reduction of $\geq 3$ points. ${ }^{41,44}$ In addition to the global score, we examined the PSQI 3-factor scoring system developed by Cole, which collapses the original 7 subscales into 3 domains: sleep efficacy (sleep duration and habitual sleep efficiency), perceived sleep quality (subjective sleep quality, sleep latency, and sleep medication use), and daily disturbances (sleep disturbances and daytime dysfunction). ${ }^{45,46}$

We calculated change scores for overall sleep quality by subtracting the baseline PSQI global and subscores from the 12- and 52-week scores. Thus, negative PSQI change-scores indicate improvements in overall sleep quality.

\section{Predictor Variables}

Baseline sociodemographic characteristics included age, sex, employment (currently employed, unemployed), and education $(\geq$ high school, $<$ high school). Additional clinical predictor variables included body mass index (BMI, $\mathrm{kg} / \mathrm{m}^{2}$ ), smoking status (current smoker, not-current smoker), and self-report (yes or no) of depression or chronic obstructive pulmonary disorder (COPD).

Back-related pain and physical function were assessed using an 11-point numerical rating scale (NRS) and the Roland-Morris Disability Questionnaire (RMDQ), respectively. ${ }^{47}$ Changes in pain and physical function scores at 6 weeks were characterized as improvements of $<10 \%, 10-30 \%$, or $\geq$ $30 \%$. Improvements $\geq 30 \%$ for pain on 11-point NRS and physical function on RMDQ are thought to be clinically meaningful. ${ }^{48,49}$

\section{Analysis}

Our primary end point was at 12 weeks, reflecting change in PSQI immediately following the intervention period. A change in PSQI score from baseline to 12 weeks was analyzed using multiple linear regression, adjusting for age and RMDQ score. Secondary analysis similarly modeled change PSQI score from baseline to 52 weeks. We assessed whether the 12- and 52-week PSQI change scores differed by treatment group using the education intervention as the reference. These analyses were repeated to calculate change-scores for each of the seven individual domains of PSQI and the three factors previously described. ${ }^{45,46}$ We also stratified changes in the PSQI Global Score models by race and sex, to assess for potential effect modification, based on previous findings suggesting sleep quality may vary by race and sex. ${ }^{50,51}$
We performed univariate logistic regressions to explore whether treatment arm, baseline characteristics, and clinically meaningful improvements in pain or physical function at 6 weeks were associated with favorable sleep outcomes ( $\geq 3$ point improvement on PSQI). The likelihood of response at 12 and 52 weeks, by participant characteristics, was presented as odds ratios (ORs) and $95 \%$ confidence intervals.

The analytic sample consisted of all participants with a response to at least one component of the PSQI question, for each time point. Thus, a complete case analysis was conducted (Appendix Table 4). To address missing data, we performed sensitivity analyses using two methods of multiple imputation, assuming that data on the covariates and outcome were missing at random. The first approach used multiple imputation for the entire sample, regardless of the treatment arm, while for the second, we employed multiple imputation separately by treatment arm. The latter method has been shown to reduce bias in the assessment of treatment effect, when there appears to be differential loss to follow-up between intervention groups. ${ }^{52}$

All analyses were performed using SAS 9.4 (SAS Cary, $\mathrm{NC})$.

\section{RESULTS}

\section{Baseline Characteristics}

Baseline characteristics are described in detail elsewhere. ${ }^{39}$ Table 1 presents the baseline characteristics. Among the 320 participants, most were female (64\%), non-white $(82 \%)$, and middle-aged (mean age $=46.0[\mathrm{SD}=10.7]$ years). Participants had high sleep disturbance scores (mean PSQI score $=10.2$ $[\mathrm{SD}=3.9])$ and nearly all $(92 \%)$ met the threshold definition for poor sleep quality. Baseline covariates were similar between groups, apart from the RMDQ. Appendix Table 5 presents the PSQI subscores.

\section{Change in Sleep Quality at 12 and 52 Weeks}

Table 2 displays within- and between-group treatment differences in PSQI change-scores for the 287 and 255 participants in the complete case analysis at 12 and 52 weeks, respectively. After adjustments for age and baseline RMDQ scores, all groups modestly improved by 12 weeks. The PSQI global scores in the yoga and PT groups tended to improve more than the education group $(\mathrm{MD}=-0.63,95 \% \mathrm{CI}-1.75,0.49$ and $-0.35,95 \% \mathrm{CI}-$ $1.51,0.80$, respectively), but these changes were not statistically significant. Changes in PSQI over 52 weeks are plotted in Figure 1. By 52 weeks, the improvements in sleep (as measured by PSQI scores) are significantly better in the yoga compared with the education group ( $\mathrm{MD}=-1.46,95 \% \mathrm{CI}-2.90,-0.03$ ) and tended to be larger in PT compared with the education group $(\mathrm{MD}=-1.00,95 \% \mathrm{CI}-2.47,0.47)$. Sleep outcomes were similar and not statistically different between yoga and PT at both 12 and 52 weeks. Imputation-based sensitivity analyses yielded similar results. 
Table 1 Baseline Characteristics of 320 Study Participants Randomized to Yoga, Physical Therapy, or Education

\begin{tabular}{|c|c|c|c|}
\hline & Yoga $(N=127)$ & Physical therapy $(N=129)$ & Education $(N=64)$ \\
\hline Age, mean (SD) & $46.7(10.2)$ & $46.0(11.4)$ & $44.3(10.3)$ \\
\hline Female*, $N(\%)$ & $72(56.7)$ & $90(69.8)$ & $42(65.6)$ \\
\hline \multicolumn{4}{|l|}{ Race $^{*}, N(\%)$} \\
\hline White & $30(23.6)$ & $17(13.2)$ & $11(17.2)$ \\
\hline Non-white & $97(76.4)$ & $112(86.8)$ & $53(82.8)$ \\
\hline \multicolumn{4}{|l|}{ Ethnicity, N (\%) } \\
\hline Hispanic & $20(15.7)$ & $17(13.2)$ & $6(9.4)$ \\
\hline Non-Hispanic & $107(84.3)$ & $112(86.8)$ & $58(90.6)$ \\
\hline BMI, mean (SD) & $30.5(6.7)$ & $32.4(7.3)$ & $31.8(8.0)$ \\
\hline Back pain intensity $^{\dagger}$, mean (SD) & $7.1(1.5)$ & $7.2(1.5)$ & $7.0(1.4)$ \\
\hline RMDQ score*, mean (SD) & $13.9(5.6)$ & $15.6(5.1)$ & $15.0(5.0)$ \\
\hline PSQI global score, mean (SD) & $10.0(3.9)$ & $10.4(3.8)$ & $10.0(4.0)$ \\
\hline Sleep efficiency, mean (SD) & $2.71(2.02)$ & $2.72(2.05)$ & $2.90(2.07)$ \\
\hline Perceived sleep quality, mean (SD) & $4.39(1.93)$ & $4.70(1.89)$ & $4.30(2.10)$ \\
\hline Daily disturbance, mean (SD) & $2.93(1.23)$ & $3.00(1.13)$ & $2.86(1.04)$ \\
\hline Poor sleep quality,$N(\%)$ & $117(92.1)$ & $121(93.8)$ & $57(89.1)$ \\
\hline
\end{tabular}

BMI, body mass index; RMDQ, Roland-Morris Disability Questionnaire; PSQI, Pittsburgh Sleep Quality Index; SD, standard deviation

*We observed baseline between-group differences for sex, race, and $R M D Q$ ( $p$ value $=0.09,0.09$, and 0.03, respectively)

†Pain measured on 0-10 numerical rating scale

$\ddagger$ Poor sleep quality, participants with PSQI global score $\geq 5$

In the 3-factor analysis, perceived sleep quality (factor 2) was the domain most improved in the yoga and PT groups (Table 2). In Appendix Table 6, we present 12- and 52-week changes in global PSQI by sex and race. We did not observe statistically significant effect modification by race or sex at either time point.

\section{Responder Analysis}

At 12 weeks, $10 \%$ more yoga (44/125, 35\%) and PT (36/102, $35 \%$ ) participants experienced a clinically meaningful improvement in overall sleep quality (3-point PSQI change) than the education group $(15 / 60,25 \%)$, though this difference was not statistically significant (Table 3). By 52 weeks, the proportion of sleep responders were similar in all three groups (yoga, 44/108, 41\%; PT, 37/91, 41\%; education, 20/56, 36\%).

Irrespective of treatment, participants who reported a $30 \%$ improvement in pain or physical function at 6 weeks, compared with non-improvers, were more likely to report an improvement in sleep quality at both $12(\mathrm{OR}=3.51,95 \% \mathrm{CI}$ $1.73,7.11$ and $\mathrm{OR}=2.16,95 \%$ CI $1.18,3.95$, respectively)

Table 2 Sleep Outcomes at 12 and 52 weeks

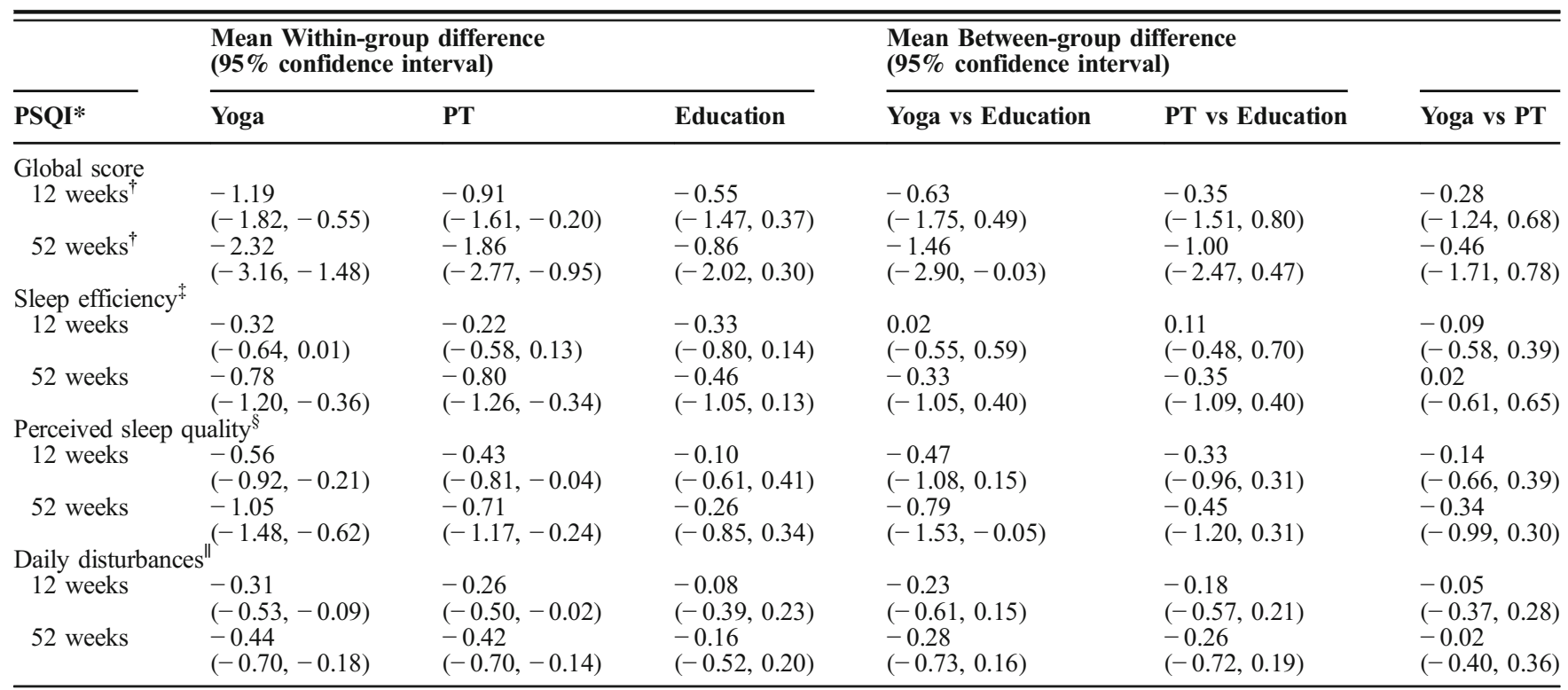

*PSOI global score and 3-factor scoring system. Complete case analysis for those with PSQI data available at $12(n=287)$ and 52 weeks $(n=255)$ †Adjusting for baseline age and Roland-Morris Disability Questionnaire score

tSleep efficiency: sleep duration and habitual sleep efficiency

SPerceived sleep quality: subjective sleep quality, sleep latency, and sleep medication use

"Daily disturbances: sleep disturbances, daytime dysfunction 


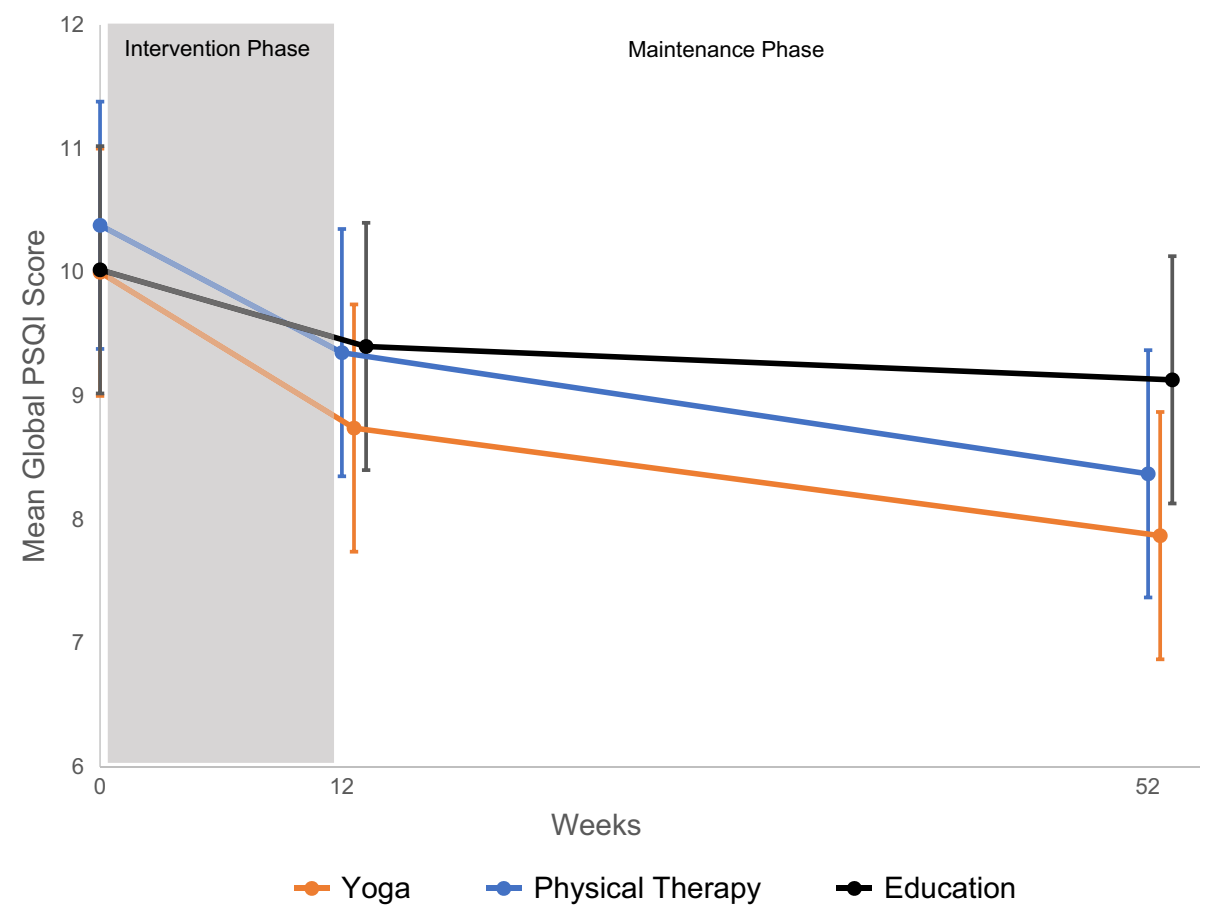

Change in PSQI global score over 52 weeks. In this complete case analysis, we used all PSQI data available at baseline $(n=320)$, 12 weeks $(n=$ $287)$, and 52 weeks $(n=255)$.

and 52 weeks $(\mathrm{OR}=1.58,95 \% \mathrm{CI} 0.77,3.23$ and $\mathrm{OR}=2.18$, $95 \%$ CI 1.19, 3.98, respectively). Additionally, female, nonwhite, and employed participants were among those likely to have improvements in sleep quality by 52 weeks. Participants who self-reported depression or COPD were less likely to improve their sleep, compared with their unaffected counterparts, at 52 weeks $(\mathrm{OR}=0.50,95 \%$ CI $0.25,0.98$ and $\mathrm{OR}=$ $0.42,95 \%$ CI $0.23,0.79$, respectively).

\section{DISCUSSION}

In this secondary analysis of a RCT of 320 adults with cLBP treated with yoga, PT, or back pain education, we found over $90 \%$ of participants had poor sleep quality prior to intervention, i.e., a global PSQI score of 5 or higher. Modest improvements in sleep quality were reported in all groups at 12 weeks and 52 weeks, but there were no statistically different benefits for yoga or PT compared with education other than improved sleep quality with yoga compared with education at 52 weeks. However, participants with clinically important improvements in back-related pain or physical function at 6 weeks, compared with others, were much more likely to have a clinically important improvement in sleep quality by 12 weeks.

While the association of cLBP and poor sleep quality is well established, ${ }^{1}$ previous studies of adults with cLBP reported a lower prevalence (e.g. 59\%) of sleep disturbance. The greater prevalence of sleep disturbance in our population may be partially explained by our predominately low-income minority sample. ${ }^{50,51}$ Factors associated with poor sleep quality that aggregate in disadvantaged communities, such as neighborhood noise, inopportune light exposure, air pollution, and irritants (e.g., tobacco smoke); perceived discrimination; and poor access to treatment, may explain the higher prevalence. ${ }^{53,54}$ Additionally, two-thirds of our participants were obese, and roughly a third were current smokers; each of these factors is associated with poor sleep. ${ }^{39,53}$

Our findings of modest improvement in sleep quality are consistent with a range of smaller studies of yoga for sleep in older adults, ${ }^{29-32}$ including those with knee osteoarthritis. ${ }^{35,36}$ Likewise, our finding of a modest improvement in sleep quality with PT is consistent with a study of 60 older adults with cLBP who received 8 weeks of PT and experienced a 1.5-point improvement in PSQI. ${ }^{22}$ However, four additional studies of mixed aerobic and resistance exercise interventions for sleep quality found larger improvements in sleep quality, i.e., 2.7 to 5.5 points. ${ }^{18-21}$ Our interventions were developed to address cLBP, and focus less on aerobic exercise compared with improving flexibility and strength. Thus, interventions focused on more vigorous exercise may explain the larger treatment effect in these studies. ${ }^{18-21}$

We found that improvements in pain or physical function mid-intervention were associated with clinically meaningful improvements in sleep quality at the end of the intervention period. There are several mechanisms supporting bi-directional associations between pain/ physical function and sleep and prior research has examined the role of sleep interventions on pain. ${ }^{1,55,56}$ It is 
Table 3 Predictors of a 3-Point Improvement in PSQI from Baseline to 12 or 52 weeks

\begin{tabular}{|c|c|c|c|c|c|}
\hline \multirow[b]{2}{*}{ Predictor } & \multirow{2}{*}{$\frac{\text { Total }}{N}$} & \multicolumn{2}{|c|}{ 12-week responders } & \multicolumn{2}{|c|}{ 52-week responders } \\
\hline & & $N(\%)$ & OR $(95 \% \mathrm{CI})$ & $N(\%)$ & OR $(95 \% \mathrm{CI})$ \\
\hline \multicolumn{6}{|l|}{ Treatment } \\
\hline Yoga & 127 & $44 / 125(35.2)$ & $1.63(0.82,3.25)$ & $44 / 108(40.7)$ & $1.24(0.64,2.41)$ \\
\hline $\mathrm{PT}$ & 129 & $36 / 102(35.3)$ & $1.64(0.80,3.33)$ & $37 / 91(40.7)$ & $1.23(0.62,2.46)$ \\
\hline Education & 64 & $15 / 60(25.0)$ & Ref & $20 / 56(35.7)$ & Ref \\
\hline \multicolumn{6}{|l|}{ Sex } \\
\hline Female & 204 & $60 / 189(31.8)$ & $0.84(0.50,1.40)$ & $77 / 179$ (43.0) & $1.64(0.93,2.88)$ \\
\hline Male & 116 & $35 / 98(35.7)$ & Ref & $24 / 76(31.6)$ & Ref \\
\hline \multicolumn{6}{|l|}{ Race } \\
\hline White & 58 & 18/54 (33.3) & $1.01(0.54,1.90)$ & $14 / 51(27.5)$ & $0.51(0.26,1.00)$ \\
\hline Non-white & 262 & 77/233 (33.1) & Ref & $87 / 204(42.7)$ & Ref \\
\hline \multicolumn{6}{|l|}{ Age group } \\
\hline$\geq 34$ & 58 & $17 / 50(34.0)$ & Ref & $22 / 44(50.0)$ & Ref \\
\hline $35-44$ & 67 & $23 / 59(39.0)$ & $1.24(0.57,2.72)$ & $24 / 51(47.1)$ & $0.89(0.40,1.99)$ \\
\hline $45-54$ & 122 & $34 / 110(30.9)$ & $0.87(0.43,1.77)$ & $30 / 98(30.6)$ & $0.44(0.21,0.92)$ \\
\hline$\geq 55$ & 73 & $21 / 68(30.9)$ & $0.87(0.40,1.89)$ & $25 / 62(40.3)$ & $0.68(0.31,1.47)$ \\
\hline \multicolumn{6}{|l|}{ Ēucation level } \\
\hline$<$ High school & 126 & 36/111 (32.4) & Ref & $60 / 100(39.2)$ & Ref \\
\hline$\geq$ High school & 191 & $57 / 173(33.0)$ & $1.02(0.62,1.70)$ & $40 / 153(40.0)$ & $0.97(0.58,1.62)$ \\
\hline \multicolumn{6}{|l|}{ Current smoker } \\
\hline No & 223 & 69/202 (34.2) & Ref & 76/183 (41.5) & Ref \\
\hline Yes & 97 & $26 / 85(30.6)$ & $0.85(0.49,1.47)$ & $25 / 72(34.7)$ & $0.75(0.43,1.32)$ \\
\hline \multicolumn{6}{|l|}{ Employed } \\
\hline No & 176 & 49/157 (31.2) & Ref & $48 / 144(33.3)$ & Ref \\
\hline Yes & 144 & $46 / 130(35.4)$ & $1.21(0.74,1.98)$ & $53 / 111(47.8)$ & $1.83(1.10,3.04)$ \\
\hline \multicolumn{6}{|l|}{ Depression } \\
\hline No & 242 & $70 / 219(32.0)$ & Ref & $84 / 195(43.1)$ & Ref \\
\hline Yes & 66 & 22/57 (38.6) & $1.34(0.73,2.45)$ & $14 / 51(27.5)$ & $0.50(0.25,0.98)$ \\
\hline \multicolumn{6}{|l|}{ COPD } \\
\hline No & 239 & $73 / 218$ (33.5) & Ref & $83 / 186(44.6)$ & Ref \\
\hline Yes & 79 & $20 / 67(29.9)$ & $0.85(0.47,1.53)$ & $17 / 67(25.4)$ & $0.42(0.23,0.79)$ \\
\hline \multicolumn{6}{|c|}{ Pain improvement, 6 weeks } \\
\hline$<10 \%$ & 77 & $20 / 75(26.7)$ & Ref & $23 / 69(33.3)$ & Ref \\
\hline $10-30 \%$ & 136 & $31 / 129(24.0)$ & $0.87(0.45,1.67)$ & $46 / 112(41.1)$ & $1.39(0.75,2.61)$ \\
\hline$>30 \%$ & 67 & $37 / 66(56.1)$ & $3.51(1.73,7.11)$ & $26 / 59(44.1)$ & $1.58(0.77,3.23)$ \\
\hline \multicolumn{6}{|c|}{ RMDQ improvement, 6 weeks } \\
\hline$<10 \%$ & 121 & 28/116 (24.1) & Ref & $33 / 103(32.0)$ & Ref \\
\hline $10-30 \%$ & 73 & $26 / 70(37.1)$ & $1.86(0.97,3.54)$ & $23 / 60(38.3)$ & $1.32(0.68,2.56)$ \\
\hline$>30 \%$ & 88 & $35 / 86(40.7)$ & $2.16(1.18,3.95)$ & $40 / 79(50.6)$ & $2.18(1.19,3.98)$ \\
\hline
\end{tabular}

OR, odds ratio; COPD, chronic obstructive pulmonary disease; RMDQ, Roland Morris Disability Questionnaire

unclear if improvements in pain or physical function caused improved sleep, or improved sleep from yoga caused improvements in pain or function. To establish directionality of these potential therapeutic mechanisms, a prospective study would be needed in adults with cooccurring cLBP and sleep dysfunction, including formal mediation analyses and measures of both pain and sleep quality more frequently (e.g., weekly) over treatment and follow-up periods."

Few studies of yoga and PT have measured long-term sleep outcomes. We found reductions in global PSQI persisted over 52 weeks in participants in the yoga and PT but not the education group. While these outcomes need to be cautiously interpreted as they were the results of secondary analyses and were not accompanied by significant changes in the proportion of individuals with a clinically meaningful improvement in PSQI, they suggest the potential for long-term improvements in sleep quality, particularly with yoga. Other trials of yoga ${ }^{26,30}$ and exercise $^{20}$ have observed similar gradual improvement over longer follow-up periods, i.e., 6 months to 2 years and support the need for long-term evaluations of effects of behavioral interventions on sleep quality.

Yoga and PT are resource and time intensive, and additional analyses of cost-effectiveness are needed. Preliminary evidence suggests yoga ${ }^{57,58}$ and $\mathrm{PT}^{59}$ are cost-effective for managing cLBP, and a cost-effectiveness analysis of the Back to Health Study is currently underway. Our yoga and PT interventions are relatively low-cost when compared with invasive procedures, such as epidural injections and surgery. In our study, the overall annual costs were $\$ 650$ and $\$ 1400$ per yoga and PT participant (unpublished), respectively. Additionally, yoga and PT interventions teach self-care strategies, which can be practiced at home at no cost. Insurance coverage for yoga and incorporation of these services in community health centers may reduce the financial burden to patients. 
Strengths of our study include a large sample size, a well-validated sleep outcome measure, abundant information on key covariates, and a 1-year follow-up period. Our sample can be considered representative with regard to describing sleep quality in low-income primarily minority adults with cLBP.

The principal limitation of our study is that this is a secondary analysis of a RCT designed to evaluate the effectiveness of yoga and PT for improving pain and back-specific function in adults with cLBP. Nonetheless, over $90 \%$ of Back to Health Study participants had poor sleep quality at baseline. Although we did not use an objective measure of sleep quality (e.g. , polysomnography) and could not identify participants with insomnia disorder, the PSQI is a commonly used, well-validated, reliable measure of sleep for patients with primary insomnia. ${ }^{43}$

Moderate loss to follow-up at 12 and 52 weeks (10\% and $20 \%$, respectively) with disproportionately greater loss to follow-up in PT is an additional limitation. Fortunately, our sensitivity analyses using multiple imputation, to evaluate bias, provided similar results. Additionally, it seems unlikely that the disproportionate loss to follow-up in the PT group was due to sleep outcomes.

Although the yoga and PT interventions were designed to improve back pain rather than sleep quality, our interventions included components thought to be important for improving sleep quality, i.e., modest exercise, meditation, relaxation. ${ }^{13,60}$ More significant improvements in sleep may potentially be achieved by tailoring yoga practices for bedtime use, or by combining yoga or PT with sleep hygiene or CBT-I. Further research is needed in this area, particularly among racial/ethnic minorities who have a high proportion of sleep disturbance, yet are underrepresented in studies on behavioral and yoga interventions for sleep.

Our findings suggest that effective treatment of cLBP may improve sleep quality. Future research on clinical interventions should further explore the interaction of improvements in back pain and sleep quality. Developing optimal interventions may hinge on improving our understanding of the associations between cLBP and poor sleep quality.

\section{CONCLUSIONS}

In a sample of low-income racially diverse adults with cLBP, over $90 \%$ reported poor sleep quality at baseline. It is important for primary care providers to be aware of the common coexistence of sleep problems with cLBP and to identify and address these co-occurring conditions. Overall, yoga and PT provided modest improvements in sleep quality. However, participants who had a clinically meaningful reduction in pain mid-intervention were three-and-a-half times as likely to have a clinically significant improvement in sleep quality at the end of the 12-week intervention period. Yoga and PT may be helpful in co-managing back pain symptoms and poor sleep quality. Future research is needed to develop and evaluate yoga and PT interventions that may maximize benefit to both of these symptomatic domains.

\begin{abstract}
Acknowledgments: We thank David Felson, MD, MPH, and the Boston University Clinical Epidemiology Research Unit for their constructive review of this paper.
\end{abstract}

Corresponding Author: Eric J. Roseen, DC, MSc; Department of Family Medicine Boston University School of Medicine and Boston Medical Center, Boston, MA, USA (e-mail: Eric.Roseen@bmc.org).

Author Contributions Drs. Roseen, Gerlovin, and Saper had full access to all of the data in the study and take responsibility for the integrity of the data and the accuracy of the data analysis. Study concept and design: Roseen, Sherman, Saper.

Acquisition, analysis, or interpretation of data: Roseen, Gerlovin, Femia, Cho, Bertisch, Redline, Sherman, Saper.

Drafting of the manuscript: Roseen.

Critical revision of the manuscript for important intellectual content: Roseen, Gerlovin, Femia, Cho, Bertisch, Redline, Sherman, Saper.

Statistical analysis: Roseen, Gerlovin.

Obtained funding: $n / a$.

Administrative, technical, or material support: Roseen, Femia, Saper. Study supervision: Roseen, Saper.

Funding Information The Back to Health Study (5RO1AT005956) was funded by the National Center for Complementary and Integrative Health (NCCIH). Dr. Roseen is supported by a Ruth L. Kirschstein National Research Service Award (1F32AT009272) from the NCCIH and by the Boston University Clinical and Translational Science Institute (CTSI) Clinical Research Training Program (1UL1TR001430). Drs. Bertisch and Redline are supported in part by NCCIH (R34 ATO08923).

\section{Compliance with Ethical Standards:}

The Boston University Medical Campus Institutional Review Board approved the study prior to data collection. All participants provided written informed consent.

Conflict of Interest: The authors declare that they do not have a conflict of interest.

Disclaimer: The funding sources had no role in the design and conduct of the study; collection, management, analysis, and interpretation of the data; preparation, review, or approval of the manuscript; and decision to submit the manuscript for publication. The contents of this manuscript are solely the responsibility of the authors and do not necessarily represent the official views of NCCIH. 


\section{APPENDIX}

Table 4 Pattern of Missing PSQI Values

\begin{tabular}{lllll}
\hline \hline PSQI & Yoga $(\boldsymbol{n}=\mathbf{1 2 7})$ & Education $(\boldsymbol{n}=\mathbf{6 4})$ & PT $(\boldsymbol{n}=\mathbf{1 2 9})$ & Total $(\boldsymbol{n}=\mathbf{3 2 0})$ \\
\hline Baseline & & & & \\
Complete & $123(97 \%)$ & $62(97 \%)$ & $123(95 \%)$ & $308(96 \%)$ \\
Incomplete & $4(3 \%)$ & $2(3 \%)$ & 0 & $12(4 \%)$ \\
Missing & 0 & 0 & $99(77 \%)$ & 0 \\
12 weeks & $122(96 \%)$ & $58(91 \%)$ & $3(2 \%)$ & $279(87 \%)$ \\
Complete & $3(2 \%)$ & $2(3 \%)$ & $27(21 \%)$ & $8(3 \%)$ \\
Incomplete & $2(2 \%)$ & $4(6 \%)$ & $87(67 \%)$ & $33(10 \%)$ \\
Missing & $104(82 \%)$ & $54(84 \%)$ & $4(3 \%)$ & $245(77 \%)$ \\
52 weeks & $3(3 \%)$ & $2(3 \%)$ & $38(29 \%)$ & $10(3 \%)$ \\
Complete & $19(15 \%)$ & $8(13 \%)$ & & $65(20 \%)$ \\
Incomplete & & & \\
Missing & & & \\
\hline
\end{tabular}

"Incomplete" indicates partial completion of survey

"Missing" indicates participant did not answer any of PSQI survey

Table 5 Unadjusted PSQI Global and Subscores for Participants Randomized to Yoga, PT, or Education Interventions at Baseline, 12 weeks, and 52 weeks

\begin{tabular}{|c|c|c|c|c|c|}
\hline & $\begin{array}{l}\text { Baseline } \\
\text { Mean (SE) }\end{array}$ & $\begin{array}{l}12 \text { weeks } \\
\text { Mean (SE) }\end{array}$ & $\begin{array}{l}52 \text { weeks } \\
\text { Mean (SE) }\end{array}$ & $\begin{array}{l}\text { 12-week change } \\
\text { Mean }(95 \% \text { CI) }\end{array}$ & $\begin{array}{l}\text { 52-week change } \\
\text { Mean }(95 \% \text { CI) }\end{array}$ \\
\hline \multicolumn{6}{|l|}{ Yoga $(n=127)$} \\
\hline PSQI global score & $10.00(0.35)$ & $8.74(0.38)$ & $7.87(0.44)$ & $-1.19(-0.59,-1.79)$ & $-2.25(-3.08,-1.42)$ \\
\hline Subjective sleep quality & $1.79(0.07)$ & $1.46(0.07)$ & $1.41(0.09)$ & $-0.31(-0.45,-0.18)$ & $-0.41(-0.58,-0.23)$ \\
\hline Sleep latency & $1.84(0.08)$ & $1.59(0.09)$ & $1.37(0.11)$ & $-0.26(-0.42,-0.10)$ & $-0.52(-0.74,-0.31)$ \\
\hline Sleep duration & $1.46(0.10)$ & $1.29(0.10)$ & $1.10(0.10)$ & $-0.15(-0.32,0.03)$ & $-0.38(-0.58,-0.19)$ \\
\hline Habitual sleep efficiency & $1.26(0.11)$ & $1.06(0.11)$ & $0.92(0.12)$ & $-0.17(-0.40,0.05)$ & $-0.37(-0.63,-0.11)$ \\
\hline Sleep disturbance & $1.79(0.06)$ & $1.66(0.06)$ & $1.62(0.07)$ & $-0.12(-0.24,0.00)$ & $-0.19(-0.35,-0.03)$ \\
\hline Sleep medication use & $0.77(0.10)$ & $0.78(0.11)$ & $0.65(0.11)$ & $0.02(-0.21,0.24)$ & $-0.09(-0.30,0.12)$ \\
\hline Daytime dysfunction & $1.16(0.08)$ & $0.95(0.08)$ & $0.91(0.08)$ & $-0.19(-0.35,-0.03)$ & $-0.24(-0.42,-0.06)$ \\
\hline \multicolumn{6}{|l|}{ PT $(n=129)$} \\
\hline PSQI global score & $10.38(0.34)$ & $9.35(0.44)$ & $8.37(0.52)$ & $-0.88(-0.12,-1.64)$ & $-1.84(-0.84,-2.83)$ \\
\hline Subjective sleep quality & $1.78(0.07)$ & $1.48(0.09)$ & $1.31(0.11)$ & $-0.27(-0.44,-0.11)$ & $-0.42(-0.65,-0.20)$ \\
\hline Sleep latency & $2.10(0.07)$ & $1.88(0.09)$ & $1.66(0.10)$ & $-0.20(-0.36,-0.04)$ & $-0.45(-0.65,-0.26)$ \\
\hline Sleep duration & $1.49(0.10)$ & $1.45(0.11)$ & $1.14(0.12)$ & $-0.02(-0.22,0.18)$ & $-0.31(-0.53,-0.10)$ \\
\hline Habitual sleep efficiency & $1.24(0.11)$ & $1.04(0.11)$ & $0.80(0.12)$ & $-0.16(-0.42,0.09)$ & $-0.51(-0.83,-0.19)$ \\
\hline Sleep disturbance & $1.89(0.05)$ & $1.73(0.06)$ & $1.69(0.08)$ & $-0.14(-0.27,-0.01)$ & $-0.22(-0.38,-0.07)$ \\
\hline Sleep medication use & $0.89(0.11)$ & $0.88(0.12)$ & $1.03(0.14)$ & $0.00(-0.25,0.25)$ & $0.16(-0.14,0.45)$ \\
\hline Daytime dysfunction & $1.11(0.07)$ & $0.92(0.08)$ & $0.80(0.08)$ & $-0.12(-0.29,0.05)$ & $-0.19(-0.35,-0.02)$ \\
\hline \multicolumn{6}{|l|}{ Education $(n=64)$} \\
\hline PSQI global score & $10.02(0.50)$ & $9.40(0.54)$ & $9.13(0.60)$ & $-0.58(0.33,-1.49)$ & $-1.04(-0.01,-2.06)$ \\
\hline Subjective sleep quality & $1.66(0.11)$ & $1.60(0.11)$ & $1.55(0.13)$ & $-0.05(-0.26,0.16)$ & $-0.14(-0.39,0.10)$ \\
\hline Sleep latency & $1.80(0.13)$ & $1.58(0.12)$ & $1.66(0.14)$ & $-0.20(-0.46,0.06)$ & $-0.18(-0.49,0.13)$ \\
\hline Sleep duration & $1.51(0.14)$ & $1.34(0.14)$ & $1.44(0.17)$ & $-0.12(-0.36,0.12)$ & $-0.19(-0.47,0.10)$ \\
\hline Habitual sleep efficiency & $1.42(0.16)$ & $1.17(0.16)$ & $1.07(0.17)$ & $-0.18(-0.44,0.09)$ & $-0.36(-0.76,0.05)$ \\
\hline Sleep disturbance & $1.84(0.08)$ & $1.73(0.09)$ & $1.60(0.11)$ & $-0.10(-0.32,0.12)$ & $-0.25(-0.48,-0.03)$ \\
\hline Sleep medication use & $0.84(0.14)$ & $1.05(0.17)$ & $0.80(0.17)$ & $0.15(-0.17,0.47)$ & $0.00(-0.31,0.31)$ \\
\hline Daytime dysfunction & $1.02(0.08)$ & $1.02(0.10)$ & $1.07(0.08)$ & $0.00(-0.21,0.21)$ & $0.07(-0.17,0.31)$ \\
\hline
\end{tabular}


Table 6 PSQI Global Score Stratified by Sex and Race

\begin{tabular}{|c|c|c|c|c|c|}
\hline \multirow{2}{*}{$\overline{~ G l o b a l ~ P S Q I * ~}$} & \multicolumn{3}{|c|}{ Mean Within-group difference ( $95 \%$ confidence interval) } & \multicolumn{2}{|c|}{$\begin{array}{l}\text { Mean Between-group difference (95\% confi- } \\
\text { dence interval) }\end{array}$} \\
\hline & Yoga & PT & Education & Yoga vs education & PT vs education \\
\hline Full sample & $(n=127)$ & $(n=129)$ & $(n=64)$ & & \\
\hline 12 weeks & $-1.19(-1.82,-0.55)$ & $-0.91(-1.61,-0.20)$ & $-0.55(-1.47,0.37)$ & $-0.63(-1.75,0.49)$ & $-0.35(-1.51,0.80)$ \\
\hline 52 weeks & $-2.32(-3.16,-1.48)$ & $-1.86(-2.77,-0.95)$ & $-0.86(-2.02,0.30)$ & $-1.46(-2.90,-0.03)$ & $-1.00(-2.47,0.47)$ \\
\hline Male & $(n=55)$ & $(n=39)$ & $(n=22)$ & & \\
\hline 12 weeks & $-1.03(-1.87,-0.19)$ & $-1.82(-2.99,-0.64)$ & $-0.24(-1.68,1.20)$ & $-0.79(-2.44,0.87)$ & $-1.58(-3.41,0.25)$ \\
\hline 52 weeks & $-1.22(-2.53,0.10)$ & $-2.43(-4.34,-0.53)$ & $0.91(-1.38,3.20)$ & $-2.12(-4.74,0.50)$ & $-3.34(-6.26,-0.42)$ \\
\hline Female & $(n=72)$ & $(n=90)$ & $(n=42)$ & & \\
\hline 12 weeks & $-1.32(-2.23,-0.42)$ & $-0.58(-1.46,0.30)$ & $-0.65(-1.83,0.53)$ & $-0.67(-2.16,0.81)$ & $0.07(-1.40,1.54)$ \\
\hline 52 weeks & $-3.01(-4.09,-1.94)$ & $-1.69(-2.73,-0.66)$ & $-1.48(-2.82,-0.13)$ & $-1.53(-3.25,0.19)$ & $-0.22(-1.91,1.47)$ \\
\hline White & $(n=30)$ & $(n=17)$ & $(n=11)$ & & \\
\hline 12 weeks & $-1.38(-2.68,-0.08)$ & $-1.72(-3.51,0.08)$ & $0.07(-2.13,2.28)$ & $-1.45(-3.98,1.08)$ & $-1.79(-4.54,0.96)$ \\
\hline 52 weeks & $-2.49(-4.02,-0.97)$ & $-1.43(-3.50,0.63)$ & $1.28(-1.55,4.12)$ & $-3.78(-6.98,-0.57)$ & $-2.72(-6.09,0.65)$ \\
\hline Non-white & $(n=97)$ & $(n=112)$ & $(n=53)$ & & \\
\hline 12 weeks & $-1.14(-1.88,-0.40)$ & $-0.76(-1.54,0.01)$ & $-0.66(-1.69,0.36)$ & $-0.47(-1.74,0.79)$ & $-0.10(-1.38,1.18)$ \\
\hline 52 weeks & $-2.30(-3.30,-1.30)$ & $-1.93(-2.95,-0.90)$ & $-1.18(-2.48,0.11)$ & $-1.11(-2.75,0.52)$ & $-0.74(-2.39,0.90)$ \\
\hline
\end{tabular}

*Adjusting for baseline age and Roland-Morris Disability Questionnaire score

\section{REFERENCES}

1. Kelly GA, Blake C, Power CK, O'Keeffe D, Fullen BM. The association between chronic low back pain and sleep: a systematic review. Clin J Pain. 2011;27(2):169-181.

2. Alsaadi SM, McAuley JH, Hush JM, Maher CG. Prevalence of sleep disturbance in patients with low back pain. Eur Spine J. 2011;20(5):737743.

3. Tang NK, Wright KJ, Salkovskis PM. Prevalence and correlates of clinical insomnia co-occurring with chronic back pain. J Sleep Res. 2007;16(1):85-95.

4. Alsaadi SM, McAuley JH, Hush JM, et al. The bidirectional relationship between pain intensity and sleep disturbance/quality in patients with low back pain. Clin J Pain. 2014;30(9):755-765.

5. Finan PH, Goodin BR, Smith MT. The association of sleep and pain: an update and a path forward. J Pain. 2013;14(12):1539-1552.

6. Jones JD, Mogali S, Comer SD. Polydrug abuse: a review of opioid and benzodiazepine combination use. Drug Alcohol Depend. 2012;125(1-2):818

7. Ho KK FP, Pinheiro MB, Silva DA, Miller CB, Grunstein R, Simic. Sleep interventions for osteoarthritis and spinal pain: a systematic review and meta-analysis of randomized controlled trials. Osteoarthritis and Cartilage. 2018.

8. Trauer JM, Gian MY, Doyle JS, Rajaratnam SM, Cunnington D. Cognitive Behavioral Therapy for Chronic Insomnia: A Systematic Review and Meta-analysis. Ann Intern Med. 2015;163(3):191-204.

9. Hayden JA, van Tulder MW, Tomlinson G. Systematic review: strategies for using exercise therapy to improve outcomes in chronic low back pain. Ann Intern Med. 2005; 142(9):776-785.

10. Cramer H, Lauche R, Haller H, Dobos G. A systematic review and metaanalysis of yoga for low back pain. Clin J Pain. 2013;29(5):450-460.

11. Wieland LS, Skoetz N, Pilkington K, Vempati R, D'Adamo CR, Berman BM. Yoga treatment for chronic non-specific low back pain. Cochrane Database Syst Rev. 2017;1:CD010671.

12. Gaseem A, Wilt TJ, McLean RM, Forciea MA, Clinical Guidelines Committee of the American College of P. Noninvasive Treatments for Acute, Subacute, and Chronic Low Back Pain: A Clinical Practice Guideline From the American College of Physicians. Ann Intern Med. 2017; 166(7):514-530

13. Irish LA, Kline CE, Gunn HE, Buysse DJ, Hall MH. The role of sleep hygiene in promoting public health: A review of empirical evidence. Sleep Med Rev. 2015;22:23-36.

14. Freburger JK, Carey TS, Holmes GM, et al. Exercise prescription for chronic back or neck pain: who prescribes it? who gets it? What is prescribed? Arthritis Rheum. 2009;61(2):192-200.

15. Yang P-Y, Ho K-H, Chen H-C, Chien M-Y. Exercise training improves sleep quality in middle-aged and older adults with sleep problems: a systematic review. Journal of Physiotherapy. 2012;58(3):157-163.
16. Rogers LQ, Courneya KS, Oster RA, et al. Physical Activity and Sleep Quality in Breast Cancer Survivors: A Randomized Trial. Med Sci Sports Exerc. 2017;49(10):2009-2015.

17. Guthrie KA, Larson JC, Ensrud KE, et al. Effects of Pharmacologic and Nonpharmacologic Interventions on Insomnia Symptoms and Selfreported Sleep Quality in Women With Hot Flashes: A Pooled Analysis of Individual Participant Data From Four MsFLASH Trials. Sleep. 2018;41(1).

18. King AC, Oman RF, Brassington GS, Bliwise DL, Haskell WL Moderate-intensity exercise and self-rated quality of sleep in older adults. A randomized controlled trial. JAMA. 1997;277(1):32-37.

19. Singh NA, Clements KM, Fiatarone MA. A randomized controlled trial of the effect of exercise on sleep. Sleep. 1997;20(2):95-101.

20. Vaz Fragoso CA, Miller ME, King AC, et al. Effect of Structured Physica Activity on Sleep-Wake Behaviors in Sedentary Elderly Adults with Mobility Limitations. J Am Geriatr Soc. 2015;63(7):1381-1390.

21. Reid KJ, Baron KG, Lu B, Naylor E, Wolfe L, Zee PC. Aerobic exercise improves self-reported sleep and quality of life in older adults with insomnia. Sleep Med. 2010;11(9):934-940.

22. Eadie $\mathbf{J}$, van de Water AT, Lonsdale $\mathbf{C}$, et al. Physiotherapy for sleep disturbance in people with chronic low back pain: results of a feasibility randomized controlled trial. Arch Phys Med Rehabil. 2013;94(11):20832092.

23. Clarke TC, Black LI, Stussman BJ, Barnes PM, Nahin RL. Trends in the use of complementary health approaches among adults: United States, 2002-2012. Natl Health Stat Report. 2015(79): 1-16.

24. Fang $\mathbf{R}, \mathbf{L i} \mathbf{X}$. A regular yoga intervention for staff nurse sleep quality and work stress: a randomised controlled trial. J Clin Nurs. 2015;24(2324):3374-3379.

25. Cohen L, Warneke C, Fouladi RT, Rodriguez MA, Chaoul-Reich A. Psychological adjustment and sleep quality in a randomized trial of the effects of a Tibetan yoga intervention in patients with lymphoma. Cancer 2004;100(10):2253-2260.

26. Bower JE, Garet D, Sternlieb B, et al. Yoga for persistent fatigue in breast cancer survivors: a randomized controlled trial. Cancer. 2012;118(15):3766-3775.

27. Mustian KM, Sprod LK, Janelsins M, et al. Multicenter, randomized controlled trial of yoga for sleep quality among cancer survivors. $J$ Clin Oncol. 2013;31(26):3233-3241.

28. Cramer H, Pokhrel B, Fester C, et al. A randomized controlled bicenter trial of yoga for patients with colorectal cancer. Psychooncology. 2016;25(4):412-420.

29. Chen KM, Chen MH, Chao HC, Hung HM, Lin HS, Li CH. Sleep quality, depression state, and health status of older adults after silver yoga exercises: cluster randomized trial. Int $J$ Nurs Stud. 2009;46(2): 154-163.

30. Chen KM, Chen MH, Lin MH, Fan JT, Lin HS, Li CH. Effects of yoga on sleep quality and depression in elders in assisted living facilities. $J$ Nurs Res. 2010;18(1):53-61. 
31. Hariprasad VR, Sivakumar PT, Koparde V, et al. Effects of yoga intervention on sleep and quality-of-life in elderly: A randomized controlled trial. Indian J Psychiatry. 2013;55(Suppl 3):S364-368.

32. Halpern J, Cohen M, Kennedy G, Reece J, Cahan C, Baharav A. Yoga for improving sleep quality and quality of life for older adults. Altern Ther Health Med. 2014;20(3):37-46.

33. Newton KM, Reed SD, Guthrie KA, et al. Efficacy of yoga for vasomotor symptoms: a randomized controlled trial. Menopause. 2014;21(4):339346.

34. Buchanan DT, Landis CA, Hohensee C, et al. Effects of Yoga and Aerobic Exercise on Actigraphic Sleep Parameters in Menopausal Women with Hot Flashes. J Clin Sleep Med. 2017;13(1):11-18.

35. Taibi DM, Vitiello MV. A pilot study of gentle yoga for sleep disturbance in women with osteoarthritis. Sleep Med. 2011;12(5):512-517.

36. Cheung C, Wyman JF, Resnick B, Savik K. Yoga for managing knee osteoarthritis in older women: a pilot randomized controlled trial. BMC Complement Altern Med. 2014; 14: 160.

37. Kirkwood G, Rampes H, Tuffrey V, Richardson J, Pilkington K. Yoga for anxiety: a systematic review of the research evidence. Br J Sports Med. 2005;39(12):884-891; discussion 891.

38. Saper RB, Sherman KJ, Delitto A, et al. Yoga vs. physical therapy vs. education for chronic low back pain in predominantly minority populations: study protocol for a randomized controlled trial. Trials. 2014;15:67.

39. Saper RB, Lemaster C, Delitto A, et al. Yoga, Physical Therapy, or Education for Chronic Low Back Pain: A Randomized Noninferiority Trial. Ann Intern Med. 2017;167(2):85-94.

40. Moore JE LK, Von Korff M, Gonzalez VM, Laurent DD. The Back Pain Helpbook. New York: Perseus Books; 1999

41. Buysse DJ, Reynolds CF, 3rd, Monk TH, Berman SR, Kupfer DJ. The Pittsburgh Sleep Quality Index: a new instrument for psychiatric practice and research. Psychiatry Res. 1989;28(2):193-213.

42. Carpenter JS, Andrykowski MA. Psychometric evaluation of the Pittsburgh Sleep Quality Index. J Psychosom Res. 1998;45(1):5-13.

43. Backhaus J, Junghanns K, Broocks A, Riemann D, Hohagen F. Testretest reliability and validity of the Pittsburgh Sleep Quality Index in primary insomnia. J Psychosom Res. 2002;53(3):737-740.

44. Buysse DJ, Germain A, Moul DE, et al. Efficacy of brief behavioral treatment for chronic insomnia in older adults. Arch Intern Med. 2011;171(10):887-895.

45. Cole JC, Motivala SJ, Buysse DJ, Oxman MN, Levin MJ, Irwin MR. Validation of a 3-factor scoring model for the Pittsburgh sleep quality index in older adults. Sleep. 2006;29(1):112-116.

46. Hughes JM, Song $\mathbf{Y}$, Fung $\mathbf{C H}$, et al. Measuring Sleep in Vulnerable Older Adults: A Comparison of Subjective and Objective Sleep Measures. Clin Gerontol. 2018;41(2):145-157.

47. Patrick DL, Deyo RA, Atlas SJ, Singer DE, Chapin A, Keller RB. Assessing health-related quality of life in patients with sciatica. Spine (Phila Pa 1976). 1995;20(17):1899-1908; discussion 1909.

48. Ostelo RW, Deyo RA, Stratford P, et al. Interpreting change scores for pain and functional status in low back pain: towards international consensus regarding minimal important change. Spine (Phila Pa 1976). 2008;33(1):90-94.

49. Jordan K, Dunn KM, Lewis M, Croft P. A minimal clinically important difference was derived for the Roland-Morris Disability Questionnaire for low back pain. J Clin Epidemiol. 2006;59(1):45-52.

50. Chen $\mathbf{X}$, Wang $\mathbf{R}$, Zee $\mathbf{P}$, et al. Racial/Ethnic Differences in Sleep Disturbances: The Multi-Ethnic Study of Atherosclerosis (MESA). Sleep. 2015;38(6):877-888.

51. Pearson NJ, Johnson LL, Nahin RL. Insomnia, trouble sleeping, and complementary and alternative medicine: Analysis of the 2002 national health interview survey data. Arch Intern Med. 2006;166(16):1775-1782.

52. Sullivan TR, White IR, Salter AB, Ryan P, Lee KJ. Should multiple imputation be the method of choice for handling missing data in randomized trials? Stat Methods Med Res. 2018;27(9):2610-2626.

53. Kingsbury JH, Buxton OM, Emmons KM. Sleep and its Relationship to Racial and Ethnic Disparities in Cardiovascular Disease. Curr Cardiovasc Risk Rep. 2013;7(5).

54. Hicken MT, Lee H, Ailshire J, Burgard SA, Williams DR. "Every shut eye, ain't sleep": The role of racism-related vigilance in racial/ethnic disparities in sleep difficulty. Race Soc Probl. 2013;5(2):100-112.

55. Vitiello MV, McCurry SM, Shortreed SM, et al. Short-term improvement in insomnia symptoms predicts long-term improvements in sleep, pain, and fatigue in older adults with comorbid osteoarthritis and insomnia. Pain. 2014;155(8): 1547-1554.

56. Salwen JK, Smith MT, Finan PH. Mid-Treatment Sleep Duration Predicts Clinically Significant Knee Osteoarthritis Pain reduction at 6 months: Effects From a Behavioral Sleep Medicine Clinical Trial. Sleep. 2017;40(2).

57. Chuang LH, Soares MO, Tilbrook H, et al. A pragmatic multicentered randomized controlled trial of yoga for chronic low back pain: economic evaluation. Spine (Phila Pa 1976). 2012;37(18): 1593-1601.

58. Aboagye E, Karlsson ML, Hagberg J, Jensen I. Cost-effectiveness of early interventions for non-specific low back pain: a randomized controlled study investigating medical yoga, exercise therapy and self-care advice. J Rehabil Med. 2015;47(2):167-173.

59. Torstensen TA, Ljunggren AE, Meen HD, Odland E, Mowinckel P, Geijerstam S. Efficiency and costs of medical exercise therapy, conventional physiotherapy, and self-exercise in patients with chronic low back pain. A pragmatic, randomized, single-blinded, controlled trial with 1year follow-up. Spine (Phila Pa 1976). 1998;23(23):2616-2624.

60. Black DS, O'Reilly GA, Olmstead R, Breen EC, Irwin MR. Mindfulness meditation and improvement in sleep quality and daytime impairment among older adults with sleep disturbances: a randomized clinical trial. JAMA Intern Med. 2015;175(4):494-501.

Publisher's Note: Springer Nature remains neutral with regard to jurisdictional claims in published maps and institutional affiliations. 